\title{
Gambaran menstruasi atlit basket di SMAN 9 Manado
}

\author{
${ }^{1}$ Lia M. Tanudjaja \\ ${ }^{2}$ Hedison Polii \\ ${ }^{2}$ Herlina I. S. Wungouw
}

\author{
${ }^{1}$ Kandidat Skripsi Fakultas Kedokteran Universitas Sam Ratulangi Manado \\ ${ }^{2}$ Bagian Fisiologi Fakultas Kedokteran Universitas Sam Ratulangi Manado \\ Email: liameiviane@gmail.com
}

\begin{abstract}
Women or female involved in sport usually become athlete, and athlete usually have high levels of physical exercise, but excess of physical exercise can cause disturbances in female reproductive organ that affects menstrual cycle. Several studies have been conducted to determine the relationship between excess energy consumption due to high level of physical exercise with impaired reproductive function in female athletes such as primary amenorrhea, secondary amenorrhea, and oligomenorrhea. This study aimed to obtain the description of menstruation in female basketball athletes on SMAN 9 Manado. This was a descriptive study using a prospective cross-sectional design. Subjects taken were female students from SMAN 9 Manado who met the inclusion criteria. Instrument that used are physical exercise and menstruation questionnaire. The result showed that 16 subjects had normal menstrual cycle, 12 subjects experienced polymenorrhea, 4 subjects experienced oligomenorrhea, and 1 subject had experienced secondary amenorrhea. Conclusion: Most of the female basketball athletes of SMAN 9 Manado experienced polymenorrhea, some experienced oligomenorrhea, and only one athlete had experienced secondary amenorrhea.
\end{abstract}

Keywords: menstrual disorder, physical exercise, amenorrhea, oligomenorrhea

\begin{abstract}
Abstrak: Wanita yang terlibat dalam dunia olahraga banyak yang menjadi atlet sehingga memiliki tingkat latihan fisik yang cukup tinggi. Latihan fisik yang tinggi dapat menyebabkan gangguan pada wanita, diantaranya dapat menimbulkan gangguan pada siklus menstruasi. Beberapa penelitian telah dilakukan untuk mengetahui hubungan antara pemakaian energi berlebih akibat latihan fisik yang tinggi dengan timbulnya gangguan fungsi reproduksi pada atlet wanita berupa amenorea primer, sekunder, dan oligomenorea. Tujuan penelitian ini untuk mengetahui gambaran menstruasi pada atlet basket siswi di SMAN 9 Manado. Metode penelitian ini deskriptif prospektif dengan desain potong lintang. Subjek penelitian ialah siswisiswi SMAN 9 Manado yang memenuhi kriteria inklusi. Instrumen yang digunakan ialah kuesioner latihan fisik dan menstruasi. Hasil penelitian didapatkan 16 subjek memiliki siklus haid normal, 12 subjek mengalami polimenorea, 4 subjek mengalami oligomenorea, dan 1 subjek pernah mengalami amenorea sekunder. Simpulan: Sebagian besar atlet basket di SMAN 9 Manado mengalami polimenorea, beberapa mengalami oligomenorea, dan hanya 1 atlit yang pernah mengalami amenorea sekunder.
\end{abstract}

Kata kunci: gangguan menstruasi, latihan fisik, amenorea, oligomenorea.

Olahraga memiliki banyak keuntungan, tetapi juga dapat menyebabkan beberapa gangguan pada atlet wanita apabila dilakukan secara berlebihan. Seorang atlet biasa mengalami berbagai gangguan fisik karena cedera. Gangguan fisik dapat terjadi pada atlet pria dan wanita, namun pada atlet wanita seringkali mengalami gangguan yang tidak akan dialami oleh para atlet pria. ${ }^{1}$ 
Latihan fisik yang berat dapat menimbulkan gangguan pada siklus menstruasi. Gangguan yang terjadi dapat berupa tidak adanya menstruasi (amenorea), penipisan tulang (osteoporosis), haid tidak teratur atau perdarahan intermenstrual, pertumbuhan abnormal dinding rahim, dan infertilitas. Sifat dan tingkat keparahan gejala tergantung pada beberapa hal seperti jenis latihan, intensitas latihan, lamanya latihan, dan laju perkembangan program pelatih. ${ }^{2}$

Amenorea lebih banyak dialami oleh wanita atlet daripada non atlet. Hal ini berhubungan dengan penggunaan energi yang berlebihan oleh atlet pada saat latihan akan mengganggu fungsi sistem reproduksi wanita yang normal. Amenorea pada atlet biasa disebut exercise-associated amenorrhea. ${ }^{1}$ Amenorea yang terjadi pada atlet muncul dalam berbagai macam frekuensi, tetapi insidennya bervariasi antara 5\% sampai 25\% tergantung pada jenis olahraga yang dijalani. ${ }^{3}$

Sebagian besar atlet wanita sering mengalami gangguan makan yang berakibat terjadinya ketidakseimbangan antara pemasukan dan pengeluaran energi sehingga terjadi kekurangan energi yang berkepanjangan. Ketidakseimbangan energi berhubungan dengan menurunnya kadar estrogen, gangguan metabolisme, dan terjadinya amenorea atau oligomenorea. ${ }^{4}$

Olahraga terdiri dari dua jenis yaitu aerobik dan anaerobik. Olahraga aerobik adalah aktivitas fisik yang dirancang untuk meningkatkan konsumsi oksigen dan meningkatkan fungsi sistem respirasi dan sistem kardiovaskular. ${ }^{5}$ American College of Sport Medicine (ACSM) menyatakan bahwa intensitas latihan harus mencapai 60-90\% dari MHR dihitung dengan rumus 220 - umur (tahun).

Berdasarkan MHR yang dicapai untuk latihan fisik ada beberapa jenis intensitas, yaitu: Intensitas sangat ringan $<50 \% \mathrm{MHR}$; intensitas ringan 50-63\% MHR; intensitas sedang 64-76\% MHR; intensias tinggi 7793\% MHR; dan intensitas sangat tinggi $>94 \%$ MHR. ${ }^{6}$

Olahraga anaerobik adalah suatu bentuk aktivitas fisik yang tidak memerlukan oksigen dalam pelaksanaannya. ${ }^{7}$ Olahraga anaerobik biasanya digunakan untuk latihan ketahanan dan diprioritaskan untuk meningkatkan kekuatan dan massa otot. $^{8}$

Gangguan haid atau biasa disebut juga dengan perdarahan uterus abnormal merupakan penyakit yang terjadi karena adanya kelainan dalam siklus haid/ menstruasi. Gangguan haid dapat dikelompokkan menjadi beberapa klasifikasi, yaitu: $:^{9,10}$

a. Gangguan lama dan jumlah darah haid

b. Gangguan siklus haid

c. Gangguan perdarahan di luar siklus haid

d. Gangguan lain yang berhubungan dengan haid

Penelitian ini bertujuan untuk mengetahui gambaran kualitatif mentruasi atlet basket di SMAN 9 Manado.

\section{METODE PENELITIAN}

Penelitian yang dilakukan bersifat deskriptif prospektif dengan menggunakan desain potong lintang (cross sectional) dimana data yang menyangkut variabel bebas dan variable terikat dikumpulkan dalam waktu bersamaan. Penelitian dilaksanakan pada bulan Oktober Desember 2015 dengan lokasi penelitian di SMAN 9 Manado.

Populasi penelitian adalah siswi-siswi di SMAN 9 Manado. Sampel penelitian adalah populasi siswi yang memenuhi kriteria inklusi. Kriteria inklusi pada penelitian ini adalah terdaftar sebagai atlet basket perempuan yang aktif di SMAN 9 Manado, bersedia menjadi responden, menandatangani informed consent dan mengisi kuesioner. Sedangkan kriteria ekslusi adalah responden yang mengonsumsi obat hormonal atau pil kontrasepsi serta responden yang mengalami gangguan menstruasi karena penyebab lain.

Data mengenai latihan fisik dan menstruasi keduanya diambil dengan menggunakan kuesioner kemudian diolah 
dengan cara deskriptif komparatif untuk membandingkan lama siklus menstruasi pada atlet basket. Deskripsi data penelitian disajikan dalam bentuk tabel dan hasil penelitian disajikan dalam bentuk distribusi frekuensi.

\section{HASIL PENELITIAN}

Tabel 1 memberikan informasi mengenai umur subjek saat mengalami menarche. Berdasarkan tabel 6 dapat dilihat bahwa paling banyak subjek yang mengalami menarche adalah pada usia 12 tahun (56,25\%). Subjek dengan jumlah paling sedikit adalah subjek dengan usia 11 dan 13 tahun (21,88\%).

Tabel 1. Distribusi Subjek Berdasarkan Usia Saat Terjadinya Menarche

\begin{tabular}{ccc} 
Menarche (Tahun) & $\mathrm{n}$ & $\%$ \\
\hline 9 & 0 & 0 \\
10 & 0 & 0 \\
11 & 7 & 21,88 \\
12 & 18 & 56,25 \\
13 & 7 & 21,88 \\
Total & 32 & 100 \\
\hline
\end{tabular}

Tabel 2 memberikan informasi mengenai subjek yang mengalami amenorea. Berdasarkan tabel 7 dapat dilihat bahwa dari 32 orang, yang mengalami Amenorea sebanyak 1 orang (3,13\%). Subjek yang tidak mengalami amenorea sebanyak 31 orang $(96,88 \%)$.

Tabel 2. Distribusi Subjek Berdasarkan Terjadinya Amenorea Sekunder

\begin{tabular}{ccc} 
Amenorea & $\mathrm{n}$ & $\%$ \\
\hline Ya & 1 & 3,13 \\
Tidak & 31 & 96,88 \\
Total & 32 & 100 \\
\hline
\end{tabular}

Tabel 3 memberikan informasi mengenai lama satu siklus haid yang dialami subjek. Berdasarkan tabel 8 dapat dilihat bahwa subjek dengan siklus 21-35 hari (polimenorea) memiliki jumlah terbanyak, yaitu berjumlah 16 orang (50\%). Subjek dengan jumlah paling sedikit adalah subjek dengan siklus haid lebih dari 35 hari (oligomenorea), yaitu sebanyak 4 orang (12,5\%).

Tabel 3. Distribusi Subjek Berdasarkan Lama Siklus Haid

\begin{tabular}{ccc} 
Lama Satu Siklus (Hari) & $\mathrm{n}$ & $\%$ \\
\hline$<21$ & 12 & 37,5 \\
$21-35$ & 16 & 50 \\
$>35$ & 4 & 12,5 \\
Total & 32 & 100 \\
\hline
\end{tabular}

\section{BAHASAN}

Berdasarkan hasil penelitian didapatkan bahwa total terdapat 16 subjek (50\%) yang mengalami gangguan siklus haid yaitu berupa polimenorea sebanyak 12 subjek (37,5\%) dan oligomenorea sebanyak 4 subjek (12,5\%). Didapatkan juga bahwa terdapat 1 subjek yang pernah mengalami amenorea sekunder.

Subjek dengan amenorea primer tidak ditemukan pada penelitian kali ini. Hal ini dapat dilihat dari usia para atlet basket saat mendapatkan menstruasi pertama kali atau menarche yaitu dari usia 11 sampai 13 tahun (Tabel 1). Tidak adanya amenorea primer dapat disebabkan karena atlet memulai olahraga atau latihan fisik intensitas tinggi setelah mereka mengalami menarche sehingga tidak didapatkan efek penurunan pada GnRH yang dapat menyebabkan terjadinya amenorea primer.

Amenorea sekunder yang terjadi pada atlet di penelitian ini dapat disebabkan karena adanya penurunan pulsatil $\mathrm{LH}$ atau dengan kata lain tidak adanya lonjakan LH sehingga kadar LH di dalam tubuh sangat rendah. Hal ini dapat menyebabkan tidak terjadinya ovulasi yang mengakibatkan terjadinya amenorea sekunder. Penurunan pulsatil LH ini diakibatkan karena penggunaan energi yang tidak diimbangi dengan pemasukan energi yang adekuat sehingga menyebabkan hipoestrogen dan berakibat pada penurunan pulsatil GnRH.

Pada penelitian ini didapatkan juga 
subjek yang mengalami oligomenorea sebanyak 4 orang (12,5\%) (Tabel 3). Hal ini menunjukkan bahwa penggunaan energi yang tidak seimbang juga dapat menyebabkan penurunan pulsatil GnRH dalam hal ini FSH yang mengakibatkan terjadinya pemanjangan fase folikuler. Sesuai dengan penelitian Quah tahun 2009 pada atlet non-leannes sport di Malaysia dengan hasil 14,3\% atlet yang mengalami oligomenorea. $^{11}$

Berdasarkan Tabel 3. ditemukan pula subjek yang mengalami polimenorea sebanyak 12 orang $(37,5 \%)$. Hal ini dapat disebabkan karena adanya siklus anovulasi yang sering ditemukan pada siklus seksual saat pubertas. Siklus anovulasi ini terjadi karena lonjakan LH praovulasi yang tidak cukup besar sehingga ovulasi tidak berlangsung. Tidak adanya ovulasi menyebabkan perubahan yaitu korpus luteum yang gagal berkembang yang mengakibatkan hampir tidak adanya sekresi progesteron selama bagian akhir dari siklus dan berakibat pada memendeknya fase luteal sehingga siklus akan memendek beberapa hari.

\section{SIMPULAN}

Berdasarkan hasil penelitian dan bahasan dapat disimpulkan bahwa gambaran menstruasi atlet basket di SMAN 9 Manado ialah 16 subjek memiliki gangguan pola siklus haid, yaitu polimenorea 12 subjek, oligomenorea 4 subjek, dan didapatkan pula 1 subjek pernah mengalami amenorea sekunder.

\section{DAFTAR PUSTAKA}

1. Handjaja M. Amenore pada atlet. Surabaya: Fakultas Kedokteran Universitas Wijaya Kusuma, 2010; p. 1.

2. Georgia Reproductive Specialist. Menstrual disturbances infemale athletes. 2007 (cited: 18 September 2015). Available from:www.ivf.com/amenath.html.

3. Warren MP. Health issues for women athletes: exercise-induced amenorrhea. Journal of Clinical Endocrinology \& Metabolism. 1999;84(6):1892-6.

4. Cobb KL, Bachrach LK, Greendale G, Marcus R, Neer RM, Nieves J, et al. disordered eating, menstrual irregularity, and bone mineral density infemale runners. Medicine and Science in Sports Exercise. 2003;35:711-19.

5. Gale Encyclopedia of Medicine. Aerobis exercise. 2008 [cited 24 September 2015]. Available from: http://medical.dictionary.thefreedictio nary.com/aerobic.

6. American College of Sport Medicine (ACSM). 2009. ACSM's guidelines for exercise testing and prescripstion. 8th ed. New York: Williams \& Wilkins.

7. Fisiologi otot. In: Sherwood L. Fisiologi manusia dari sel ke sistem. Edisi 6. Jakarta: EGC; 2014. h. 298-300.

8. Cleveland Clinic. Exercise and weight control. 2015 [cited 24 September2015]. Available from: http://my.clevelandclinic.org/heart/pr evention/exercise/ex_wtcontrol.aspx.

9. Hendarto H. Gangguan haid/perdarahan uterus abnormal. Dalam: Anwar M, Baziad A, Prabowo RP, penyunting. Ilmu kandungan (3rd ed). Jakarta: Bina Pustaka Sarwono Prawirohardjo; 2011; p. 161-85.

10. Sistem reproduksi. In: Sherwood L. Fisiologi manusia dari sel ke sistem. Edisi 6. Jakarta: EGC; 2014. p. 83370.

11.Quah YV, Poh BK, Ng LO, Noor MI. The female athlete triad among elite Malaysian athletes: prevalence and associated factors. Asia Pacific J ClinNutrition. 2009;18(2):200-8. 